\title{
Statement for Diabetes Guideline Has Been on Discussion for Future Better Lives
}

\author{
Hiroshi Bando* \\ Medical Research, Tokushima University, Japan
}

Submission: April 13, 2018; Published: May 16, 2018

*Corresponding author: Hiroshi Bando, Medical Research, Tokushima University, Japan; Tel: +81-90-3187-2485; Fax: +81-88-603-1030; Email: pianomed@bronze.ocn.ne.jp

Keywords: Diabetes guideline; American diabetes association (ADA); American college of physicians (ACP)

\section{Short Communication}

The number of diabetic patients in the world has been about 425 million, including 110 million in China, 73 million in India, and 30 million in United States [1]. In Japan, the number of diabetic patients has been steadily increasing, with 604 million in 1990, 714 million in 2000, 830 million in 2010, and it is estimated to rise to 971 million in 2030 [2]. Increase in diabetes has been related to many factors such as obesity, metabolism, flailty, modernized meal and lifestyle change with aging [3]. In other words, lots of axes and heterogeneities has been present in the pathophysiology of diabetes. Consequently, various discussions have been continued for the guidelines on diabetes.

Historically speaking, there were various comments or perspectives on diabetes guidelines. The American College of Physicians (ACP) recently released official comments concerning diabetes [4]. Among them, Statement 2 was that clinicians should set the management goal for HbA1c in most type 2 diabetic patients to be $7 \%$ or more and less than $8 \%$. This evoked surprising responses in diabetic management in the world, and it made a paradigm change for the treatment of diabetic patients [4].

The main purpose and target of diabetes therapy is the prevention of complications [5]. For years, the endpoint of many clinical trials is to lower blood glucose levels, but intensive treatments aimed at lowering the $\mathrm{HbA1c}$ to less than $6.5 \%$ are often accompanied by hypoglycemia as a side effect. At the same time, intensive regimens have not shown a reduction of cardiovascular complications in the long term [6-10]. For example, the action to control cardiovascular risk in diabetes (ACCORD) trial was prematurely discontinued, following the observation of an increase in overall mortality, cardiovascularrelated deaths, and severe hypoglycemic events [6]. The Action in Diabetes and Vascular disease; Preterax and Diamicron-MR
Controlled Evaluation (ADVANCE) study also failed to show a statistically significant clinical benefit, while more adverse effects were seen among those who achieved a median HbA1c level of $6.4 \%$ [7]. More intensive treatments with tight glycemic control targets are more costly and associated with increased patient burdens. Only Hollan et al. [11] reported a long-term benefit with intensive therapy in the United Kingdom prospective diabetes study (UKPDS) after 10 years of intervention.

Among the diabetes guidelines, one method would be roughly classifying therapeutic agents into oral or injection medicine. This way was used once in Japan. An advantage may be considering adaptation for each patient taking action mechanism, and the disadvantage is that the scientific basis for the organ protective effect is not taken into consideration. In the actual clinical setting, there is an advantage that choice of medicine is more appropriate and easier to select if there is rank ordering of medicine.

On the other hand, current ADA recommendation clearly showed the idea of thinking separately between the initial prevention of cardiovascular disease and the prevention of recurrence in the treatment for diabetes [12]. Some of the agents that have been beneficial or potentially beneficial to atherosclerotic cardiovascular disease such as kanaglifujin, empagliflozin and liraglutide. These are also beneficial for the progression of diabetic kidney disease. In addition, the American Clinical Endocrine Association/ Recommendation of the American Endocrine Association (AACE / ACE) [13] have stated from 2016 that hierarchy treatment is recommended. In the case of monotherapy, the predominance order would be metformin, GLP - 1 receptor agonist and SGLT2 inhibitors already in 2016. It seems that the recommendation of AACE / ACE seems to confirm the recommendation of current ADA comment. 
The algorithm for diabetes medication has been recently changing. The American Diabetes Association (ADA) announces comments at the beginning of each year concerning clinical practice recommendations for diabetes. It is "Standards of Medical Care in Diabetes" and includes the components of diabetes care, general treatment goals and guidelines, and tools to evaluate quality of care. Pharmacotherapy section would useful for annually changed content according to the current evidences.

In case of T1DM, there are not changes during 2017$2018[12,14]$. On contrast, the standard algorithm for T2DM was changed and seems to be the important $[12,14]$. In the announcement in 2017 it was stated as follows. If type 2 diabetic patients have insufficient glycemic control for a long time and have a history of arteriosclerotic cardiovascular disease, administration of empargliflozin and liraglutide should be considered. Because both are shown to reduce cardiovascular death and total mortality. In the 2018 version, the condition that "If blood glucose control is not sufficient for long term" was deleted from this part. This suggests that administration of both drugs is recommended in wider situations from now.

Furthermore, the recommendation up to the 2017 version followed the joint algorithm of the ADA/ European Diabetes Society (EASD) 2012 [15]. That is, metformin is used as an initiator, and various drugs are listed as horizontal lines such as SU drug, thiazolidine drug, DPP-4 inhibitor, SGLT2 inhibitor, GLP-1 receptor agonist and basal insulin. On the other hand, recommendations were changed in the 2018 edition. Metformin is used as a single agent. When HbA1c is $9 \%$ or more, 2 agents with metformin + other drug are used. When HbA1c is $10 \%$ or more, 3 agents with metformin + other drugs or insulin therapy would be considered.

Thus, regarding the process of diabetes guidelines, comments have been made from different positions in each country and each organization. In the United States, there were some guidelines and statements on diabetes guidelines, including the American Diabetes Association (ADA), the American Society of Clinical Endocrinology, and the American Endocrine Society (AACE / ACE). However, there was a difference in the contents, and confusion was actually seen in the clinical setting.

Therefore, the Clinical Guidelines Committee of the ACP independently evaluated several guidelines, and released a statement on ACP's own HbA1c management goal. ACP is an authoritative conference and highly reliable for years. Unlike ADA and AACE / ACE guidelines, the statement of ACP is extremely shocking, with a management goal of type 2 diabetes patients under medication of $7 \%$ to $8 \%$ HbA1c [16].

Prior to presentation, ACP examined the guidelines for the existing HbA1c management objectives of six academic organizations. The score was calculated as the full point was 7. The evaluation of AACE / ACE [17] and ADA [18] was lower (2.8 and 3.7), the other 4 organizations, the Institute for Clinical
Systems Improvement (ICSC) [19], the UK National Clinical Evaluation laboratory (NICE) [20], Scottish University guideline network (SIGN) [21], US Department of Veterans Affairs and US Department of Defense guidelines (VA / DoD) [22] was evaluated rather higher as $5.3,5.7,5.8,5.7$, respectively.

As mentioned above, there are five famous clinical studies based on ACP and the above six guidelines. They are

1) UKPDS 33, 34,

2) UKPDS 80,

3) ACCORD.

4) ADVANCE,

5) VADT, and the general features would be described briefly.

On UKPDS 33 and 34, intensive therapy (target fasting blood glucose $<108 \mathrm{mg} / \mathrm{dL}$ ) and conventional therapy (diet / exercise center) were compared [23,24]. Microvascular and macrovascular events showed a significant decrease (relative risk reduction: 12\%) in the intensive therapy intervention with SU drugs and insulin (attained HbA1c 7.0\%), compared with conventional therapy $(7.9 \%$ of the same). These were due to microvascular impairment, and on contrast, there was no significant decrease in macrovascular events. Meanwhile, intensive therapy intervention with metformin (attained HbA1c $7.4 \%$ ) significantly reduced microvascular and macrovascular events (relative risk reduction 32\%) as compared with conventional therapy $(8.0 \%)$, furthermore it reduced all deaths significantly (36\% of the same).

UKPDS 80 was follow-up for 10 years after completion of UKPDS 33 and 34 [23-25]. UKPDS 33 and 34 also showed a Legacy effect that a significant decrease in diabetes-related events and the risk of total mortality was confirmed in the former intensive therapy group, and that the previous intensive therapy was subsequently maintained as a heritage [25].

ACCORD: Intensive therapy (target $\mathrm{HbA} 1 \mathrm{c}<6.0 \%$, reached HbA1c 6.4\%) was compared with conventional therapy (target HbA1c 7.0 to $7.9 \%$, reached HbA1c 7.5\%). Composite cardiovascular events, the primary endpoint, did not show a significant decrease (hazard ratio 0.90) and the deaths significantly increased (1.22) [26]. Concerning ADVANCE, Intensive therapy (target $\mathrm{HbA} 1 \mathrm{c}<6.5 \%$, reached $\mathrm{HbA} 1 \mathrm{c} 6.5 \%$ ) and conventional therapy (reached HbA1c 7.3\%) were compared. Complex microvascular and macrovascular events, which are the main endpoints, showed a significant decrease (hazard ratio 0.90 ), but no significant difference was found in macrovascular event (0.94) and mortality rate (0.93) [27].

On VADT research, intensive therapy (6.9\% of HbA1c reached) and conventional therapy ( $8.4 \%$ of the same) were compared. During the intervention period of median 5.6 years, the major endpoint which is composite cardiovascular events did not show a significant decrease. However, there was a significant decrease in the follow-up study of the $12^{\text {th }}$ year thereafter (hazard ratio 
$0.83)[28,29]$.

Based on the above-mentioned influential papers, the ACP eventually compiled this statement. Over the years, changes have been seen in the way of thinking about diabetes guidelines. In the past, patients with microvascular, macrovascular and other complications involving life expectancy, had been set more stringent HbA1c targets. However, there have been on discussion that strict HbA1c target would have profit and also harmful risk. Recent guidelines discuss the role of intensive care for the elderly in order to minimize symptoms rather than achieving a specific HbA1c goal [17,30,31].

Under these circumstances, ACP proposed to adjust the treatment of diabetes in elderly people over the age of 80 [4]. On contrast, in the 2017 American Diabetes Association (ADA) guidelines, psychosocial problems were raised in many fields such as self-management of diabetes and management of comorbidities. Physicians need to be familiar with existential therapy or holistic treatment to the extent that patient's behavioral change can be achieved. Against the statement of ACP, ADA and other association have released deep concern immediately [32,33] at the basis of 2018 guideline in December, 2017 [34]. Consequently, further discussion about adequate diabetes management in the elderly would be expected by several medical associations, leading to better QOL/ADL of diabetic patients.

\section{References}

1. World Health Organization (2016) Global report on diabetes. WHO, Geneva, Switzerland.

2. Goto A, Noda M, Inoue M, Goto M, Charvat $H$, et al. (2016) Increasing number of people with diabetes in Japan: Is this trend real?. Intern Med 55(14): 1827-1830.

3. Defronzo RA (2009) Banting Lecture. From the triumvirate to the ominous octet: a new paradigm for the treatment of type 2 diabetes mellitus. Diabetes 58(4): 773-795.

4. Americal College of Physicians. Clinical Guidelines and Recommendations. USA.

5. Ojo O (2016) An overview of diabetes and its complications. Diabetes Res Open J 2(2): e4-e6.

6. Gerstein HC, Miller ME, Genuth S, ACCORD Study Group (2011) Longterm effects of intensive glucose lowering on cardiovascular outcomes. N Engl J Med 364: 818-828.

7. Patel A, MacMahon S, Chalmers J, ADVANCE Collaborative Group (2008) Intensive blood glucose control and vascular outcomes in patients with type 2 diabetes. N Engl J Med 358(24): 2560-2572.

8. Duckworth W, Abraira C, Moritz T, VADT Investigators (2009) Glucose control and vascular complications in veterans with type 2 diabetes. $\mathrm{N}$ Engl J Med 360: 129-139.

9. UK Prospective Diabetes Study (UKPDS) Group (1998) Effect of intensive blood-glucose control with metformin on complications in overweight patients with type 2 diabetes (UKPDS 34). Lancet 352(9131): 854-865.

10. Hayward RA, Reaven PD, Wiitala WL, VADT Investigators (2015) Follow-up of glycemic control and cardiovascular outcomes in type 2 diabetes. N Engl J Med 372(23): 2197-2206.
11. Holman RR, Paul SK, Bethel MA, Matthews DR, Neil HA, et al. (2008) 10year follow-up of intensive glucose control in type 2 diabetes. $\mathrm{N}$ Engl J Med 359: 1577-1589.

12. American Diabetes Association (2018) Pharmacologic Approaches to Glycemic Treatment: Standards of Medical Care in Diabetes-2018. Diabetes Care 41(Suppl 1): S73-S85.

13. Garber AJ, American Association of Clinical Endocrinologists (AACE), American College of Endocrinology (ACE) (2016) Consensus statement by the American association of clinical endocrinologists and American college of endocrinology on the comprehensive toype 2 diabetes management algorithm-2016 executive summary. Endocr Pract 22(1): 84-113.

14. American Diabetes Association (2017) Pharmacologic Approaches to Glycemic Treatment. Diabetes Care 40(Suppl 1): S64-S74.

15. Giaccari A, Giorda CB, Riccardi G, De Micheli A, Bruno G, et al. (2012) Comment on: Inzucchi et al. Management of hyperglycemia in type 2 diabetes: a patient-centered approach. Position statement of the American Diabetes Association (ADA) and the European Association for the Study of Diabetes (EASD). Diabetes Care 35(6):1364-1379.

16. Qaseem A, Wilt TJ, Kansagara D, Horwitch C, Barry MJ, et al. (2018) Hemoglobin A1c Targets for Glycemic Control With Pharmacologic Therapy for Nonpregnant Adults With Type 2 Diabetes Mellitus: A Guidance Statement Update From the American College of Physicians. Ann Intern Med 168(8): 569-576.

17. Handelsman Y, Bloomgarden ZT, Grunberger G, Umpierrez G, Zimmerman RS, et al. (2015) American association of clinical endocrinologists and american college of endocrinology - clinical practice guidelines for developing a diabetes mellitus comprehensive care plan - 2015. Endocr Pract 21(Suppl 1):1-87.

18. American Diabetes Association (2017) Glycemic Targets Sec 6 In Standards of Medical Care in Diabetes-2017. Diabetes Care 40(Suppl 1): S48-S56.

19. Redmon B, Caccamo D, Flavin P, Michels R, Myers C, et al. (2014) Institute for Clinical Systems Improvement (ICSC). Diagnosis and Management of Type 2 Diabetes Mellitus in Adults. $\left(16^{\text {th }}\right.$ edn $)$, pp. 1-83.

20. National institute for health and care excellence (NICE) (2015) Type 2 diabetes in adults: management. NICE guideline.

21. Scottish Intercollegiate Guidelines Network (SIGN) (2017) Management of diabetes. A national clinical guideline. Healthcare Improvement Scotland.

22. Department of Veterans Affairs. Department of Defense (2017) VA/ DoD clinical practice guideline for the management of type 2 diabetes mellitus in primary care version-5.0.

23. UKPDS group (1998) Intensive blood-glucose control with sulphonylureas or insulin compared with conventional treatment and risk of complications in patients with type 2 diabetes (UKPDS 33). UK Prospective Diabetes Study (UKPDS) Group. Lancet 352(9131): 837853.

24. UKPDS group (1998) Effect of intensive blood-glucose control with metformin on complications in overweight patients with type 2 diabetes (UKPDS 34). UK Prospective Diabetes Study (UKPDS) Group. Lancet 352(9131): 854-865.

25. Holman RR, Paul SK, Bethel MA, Matthews DR, Neil HA, et al. (2008) 10year follow-up of intensive glucose control in type 2 diabetes. $\mathrm{N}$ Engl J Med 359(15): 1577-1589.

26. Action to Control Cardiovascular Risk in Diabetes Study Group (2008) Effects of intensive glucose lowering in type 2 diabetes. N Engl J Med 358(24): 2545-2559.

27. ADVANCE Collaborative Group, Patel A, MacMahon S, Chalmers J, Neal B, et al. (2008) Intensive blood glucose control and vascular outcomes in patients with type 2 diabetes. N Engl J Med 358(24): 2560-2572. 
28. Duckworth W, Abraira C, Moritz T, Reda D, Emanuele N, et al. (2009) Glucose control and vascular complications in veterans with type 2 diabetes. N Engl J Med 360(2):129-139.

29. Wiitala WL, Bahn GD, Reda DJ, Ge L (2015) Follow-up of glycemic control and cardiovascular outcomes in type 2 diabetes. $\mathrm{N}$ Engl J Med 372(23): 2197-2206.

30. Ismail-Beigi F, Moghissi E, Kosiborod M, Inzucchi SE (2017) Shifting paradigms in the medical management of type 2 diabetes: Reflections on recent cardiovascular outcome trials. J Gen Intern Med 32(9): 10441051.

31. The Management of Type 2 Diabetes Mellitus in Primary Care Work Group (2017) VA/DoD clinical practice guideline for the management of type 2 diabetes mellitus in primary care. Version 5.0 .
32. ADA (2018) American Diabetes Association® Deeply Concerned About New Guidance from American College of Physicians Regarding Blood Glucose Targets for People with Type 2 Diabetes.

33. ADA (2018) The American Diabetes Association $®$, the American Association of Clinical Endocrinologists, the American Association of Diabetes Educators and the Endocrine Society Strongly Disagree with the American College of Physicians' Guidance for Higher Blood Glucose Targets for People with Type 2 Diabetes. USA.

34. ADA (2018) Standards of Medical Care in Diabetes. Diabetes Care 41(Suppl 1): 1-172.

\section{Your next submission with Juniper Publishers will reach you the below assets}

- Quality Editorial service

- Swift Peer Review

- Reprints availability

- E-prints Service

- Manuscript Podcast for convenient understanding

- Global attainment for your research

- Manuscript accessibility in different formats ( Pdf, E-pub, Full Text, Audio)

- Unceasing customer service

Track the below URL for one-step submission https://juniperpublishers.com/online-submission.php 